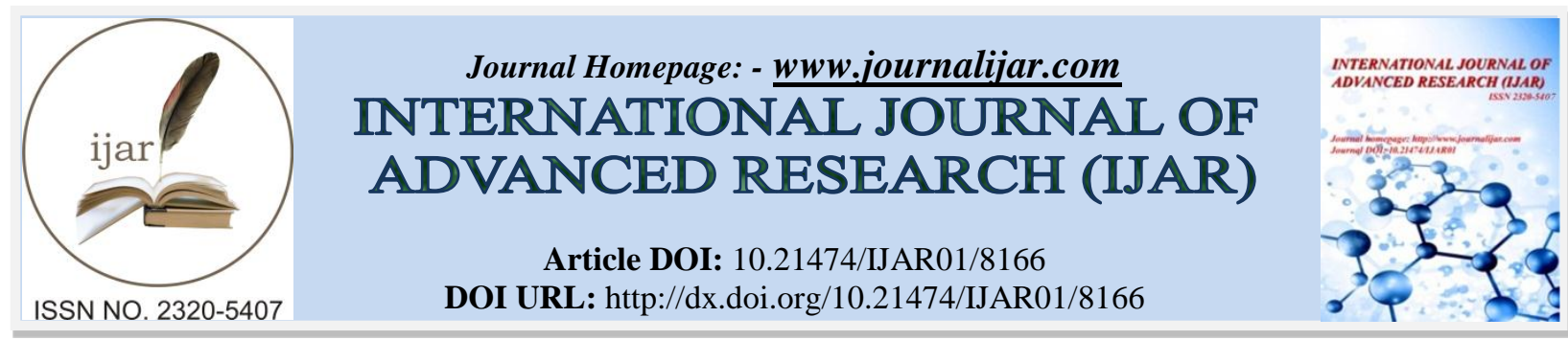

RESEARCH ARTICLE

\title{
FREQUENCY OF HYPERCAPNY WITH NORMAL PULSE OXYMETRY, DURING THE POST- ANESTHETIC PERIOD, IN PATIENTS SUBJECTED TO SURGERY UNDER GENERAL ANESTHESIA.
}

\author{
Betty Sarabia Alcocer ${ }^{1}$, Luis Alberto Núñez Oreza ${ }^{2}$, Betty Mónica Velázquez Sarabia ${ }^{3}$, Priscilla Karmina \\ Velázquez Sarabia ${ }^{4}$, Paulino Tamay Segovia ${ }^{2}$, Selene Blum Domínguez ${ }^{2}$, Patricia Margarita Garma Quen ${ }^{5}$, \\ Rafael Manuel de Jesús Mex Álvarez ${ }^{5}$, and Ángel Arturo Ake Ordoñez \\ 1. Faculty of Medicine of the Autonomous University of Campeche. \\ 2. Center for Biomedical Research. Autonomous University of Campeche. \\ 3. Doctor Surgeon graduated from the Faculty of Medicine of the U.A.C. \\ 4. Law graduate and researcher. \\ 5. Faculty of Biological Chemistry. \\ 6. Student of the Licentiate Medical Surgeon.
}

\section{Manuscript Info}

Manuscript History

Received: 08 October 2018

Final Accepted: 10 November 2018

Published: December 2018

\section{Abstract}

Objective: To determine the frequency of hypercapnia with normal pulse oximetry during the post-anesthetic period in patients undergoing surgery with general anesthesia.

Material and methods: A longitudinal, prospective, observational and analytical study was conducted in patients under informed consent, not obstetric, undergoing general anesthesia in the HGEJBO, using noninvasive methods to measure carbon dioxide at the end of expiration (EtCO2) and determine the frequency of hypercapnia in the postanesthetic period.

Results: The study was performed with a total of 44 patients whose minimum age was 15 years, maximum of 84 and average of $43.2 \pm 18$ years. Of these, 36.4\% $(n=16)$ were males and 63.6\% $(n=28)$ females. Of the total sample, $13.6 \%(n=6)$ presented hypercapnia in the postoperative period. No statistically significant correlations were found between the variables.

Conclusions: A significant percentage of patients undergoing general anesthesia presented hypercapnia with normal pulse oximetry in the postoperative period. This scenario of perioperative risk is not specifically considered in conventional postoperative management, and there are even possibly precipitating conditions derived precisely from such management. It is suggested to seriously consider the inclusion of carbon dioxide monitoring in procedures performed under general anesthesia.

Copy Right, IJAR, 2018,. All rights reserved.

\section{Introduction:-}

Respiratory insufficiency (IR) can be defined as the inability to perform gas exchange due to the inadequate function of one or more essential components of the respiratory system ${ }^{1}$, and although it is necessary to mention that it is not

Corresponding Author:-Betty Sarabia Alcocer.

Address:-Faculty of Medicine of the Autonomous University of Campeche. 
the only definition that currently exists or that has existed in history recent ${ }^{2}$, if it is one of those with the most validation and consensus. There are also several classifications to catalog their variants ${ }^{3}$, for example: type 1 , or hypoxemic $(\mathrm{PaO} 2<8 \mathrm{kPa}$, normal range 10-13.3 $\mathrm{kPa})$ without hypercapnia, and type 2 , or with hypercapnia $(\mathrm{PaCO} 2>6.5 \mathrm{kPa})^{4}$, being this last of particular importance in anesthesiology, especially in the perioperative setting and in the medical management of pain based on opiods ${ }^{5,6}$ and other medications that interfere with respiratory function to a lesser extent in relation to these ${ }^{7}$.

In the practice of anesthesiology a great variety of drugs are used, which intervene with the respiratory function and its regulation mechanisms, especially in the procedures performed under general anesthesia and deep sedation; opioids, sedatives, hypnotics, inhaled anesthetics and neuromuscular relaxants ${ }^{8}$ are some examples of drugs that can predispose to the appearance of different types of respiratory failure ${ }^{9}$, and therefore to respiratory acidosis, cerebral edema and other important disorders, including coma and heart failure. death. The measurement of parameters that evaluate this function is essential to identify and manage early complications of respiratory origin, so it is not surprising that the monitoring of $\mathrm{CO} 2$ and $\mathrm{O} 2$ during the trans-anesthetic period of procedures under general anesthesia and deep sedation is strongly recommended ${ }^{10,11}$. In turn, during the post-anesthetic period, pulse oximetry, electrocardiogram, non-invasive blood pressure (NIBP) and the administration of supplemental oxygen are accepted forms of monitoring and management ${ }^{10}$, with the idea of assessing in an integral way the state of the patient and decrease the risk of complications; highlighting pulse oximetry and oxygen administration, as safety measures against complications of respiratory origin.

Currently, in first world societies, the emergence of a trend that highlights the inclusion of capnography from the moment of induction to complete post-anesthesia recovery ${ }^{12}$, including procedures cataloged as outside of the operating room ${ }^{13}$. It is a phenomenon that has not yet been reproduced in our environment, as the risk mitigation capacity and potential resource savings described in other countries have not been recognized.

The Official Mexican Standard for the practice of anesthesiology, ${ }^{10}$ and the guidelines of the American Association of Anesthesiology ${ }^{11}$, do not consider mandatory the monitoring of $\mathrm{CO} 2$ in the post-anesthetic period of patients undergoing anesthetic-surgical events under general anesthesia or deep sedation, despite the fact that hypercapnia is a well-recognized fact of respiratory failure and that by itself it can be associated with an increased risk of admission to the intensive care unit and mortality ${ }^{14,15}$. On the other hand, the omission of monitoring by capnography can form a scenario prone to complications of respiratory origin and that is also related to morbidity and mortality in intensive care units ${ }^{16,17}$, still little recognized and described in anesthesiology, but for which There are some reports of complications associating unrecognized hypercapnia in a timely manner, precisely during the post-anesthetic period, with severe complications of respiratory origin, such as the one reported in 1998 by Ayas et al. ${ }^{18}$, who describe a case of "apneic oxygenation", in which a 75-year-old woman who underwent hip arthroplasty under general anesthesia developed severe hypercapnia in the post-anesthetic period, followed by severe respiratory acidosis and coma, even when the pulse oximetry was within the physiological range (hypercapnic respiratory failure).

\section{Material And Methods:-}

Type of study: Longitudinal, prospective, observational and analytical. Universe: Patients admitted to the operating room at the HGEJBO of Campeche during the first semester of 2017. Sample: Patients admitted to the operating room, underwent general anesthesia and were candidates for observation in the Post-anesthetic Care Unit (PACU), in the period of time established. Sample size: 44 patients were obtained in total. Statistical analysis: The data were analyzed by descriptive statistics with the SPSS program, reporting absolute (n) and relative (\%) frequencies. The associations between variables were made with $\mathrm{X} 2$ and, where appropriate, Fisher's exact test (for values less than 5). The significance value was $\mathrm{p}<0.05$.

\section{Results:-}

A total of 44 patients with a minimum age of 15 years and a maximum age of 84 were included, with an average of $43.2 \pm 18$ years. Of these, $36.4 \%(n=16)$ were male and $63.6 \%(n=28)$ were female; 8 cases were eliminated because they presented exclusion criteria and / or inconsistencies at the time of sampling. The predominant characteristics of the sample according to the general variables used can be summarized as follows:

1. $70.5 \%(\mathrm{n}=35)$ classified as ASA 2 .

2. $75 \%(\mathrm{n}=33)$ scheduled for elective procedures.

3. $61.4 \%(\mathrm{n}=27)$ intervened in major surgeries. 
4. $61.4 \%(\mathrm{n}=27)$ in charge of the surgery service.

5. $23 \%(\mathrm{n}=53)$ with surgery in the abdominal area.

Table 1 shows the results of the main variables studied. It can be seen that of the sample of 44 participants, $13.6 \%$ (n $=6$ ) presented hypercapnia in the postoperative period.

Table 1:-Description of the participants $(\mathrm{N}=44)$ according to different general variables.

\begin{tabular}{|c|c|c|c|}
\hline & & $\mathbf{n}$ & $\%$ \\
\hline \multirow[b]{2}{*}{ Sex } & Female & 28 & 63.6 \\
\hline & Male & 16 & 36.4 \\
\hline \multirow{3}{*}{ ASA } & 1 & 9 & 20.5 \\
\hline & 2 & 31 & 70.5 \\
\hline & 3 & 4 & 9.1 \\
\hline \multirow[t]{2}{*}{ Type of procedure } & Elective & 33 & 75.0 \\
\hline & Urgency & 11 & 25.0 \\
\hline \multirow[t]{2}{*}{ Tipo de surgery } & Minor & 17 & 38.6 \\
\hline & Major & 27 & 61.4 \\
\hline \multirow{6}{*}{ Service in charge } & Surgery & 27 & 61.4 \\
\hline & TyO & 9 & 20.5 \\
\hline & Neurosurgery & 2 & 4.5 \\
\hline & Ophthalmology & 3 & 6.8 \\
\hline & Oncology & 2 & 4.5 \\
\hline & Maxillofacial & 1 & 2.3 \\
\hline \multirow{6}{*}{$\begin{array}{c}\text { Anatomical location of the } \\
\text { procedure }\end{array}$} & Abdomen & 23 & 52.3 \\
\hline & Head and neck & 10 & 22.7 \\
\hline & MsTs & 5 & 11.4 \\
\hline & MsPs & 4 & 9.1 \\
\hline & Tórax & 1 & 2.3 \\
\hline & Genitalia and Perineum & 1 & 2.3 \\
\hline \multirow[b]{2}{*}{ EtCO2 } & Without hypercapnia & 38 & 86.4 \\
\hline & With hypercapnia & 6 & 13.6 \\
\hline
\end{tabular}

Of the 6 patients who presented hypercapnia, $50 \%(\mathrm{n}=3)$ was classified as ASA 1 and another $50 \%$ as ASA 2; none of the cases was classified as ASA 3. 66\% $(n=4)$ occurred in elective cases of minor surgery, $50 \%(n=3)$ in head and neck procedures, mainly in patients in charge of ophthalmology services and oncology in equivalent percentages $(33 \%, \mathrm{n}=2$, respectively) (see Table 2$)$.

Table 2:-Description of the participants with hypercapnia $(\mathrm{N}=6)$ according to different general variables.

\begin{tabular}{|c|c|c|c|}
\hline & & $\mathbf{n}$ & $\%$ \\
\hline \multirow[b]{2}{*}{ Sex } & Female & 3 & 50 \\
\hline & Male & 3 & 50 \\
\hline \multirow{3}{*}{ ASA } & 1 & 3 & 50 \\
\hline & 2 & 3 & 50 \\
\hline & 3 & 0 & 0 \\
\hline \multirow[t]{2}{*}{ Type of procedure } & Elective & 4 & 66.7 \\
\hline & Urgency & 2 & 33.3 \\
\hline \multirow[t]{2}{*}{ Type of surgery } & Minor & 4 & 66.7 \\
\hline & Major & 2 & 33.3 \\
\hline \multirow{4}{*}{ Service in charge } & Ophthalmology & 2 & 33.3 \\
\hline & Oncology & 2 & 33.3 \\
\hline & Surgery & 1 & 16.7 \\
\hline & TyO & 1 & 16.7 \\
\hline \multirow{2}{*}{$\begin{array}{c}\text { Anatomical location of the } \\
\text { procedure }\end{array}$} & Head and neck & 3 & 50 \\
\hline & Abdomen & 1 & 16.7 \\
\hline
\end{tabular}




\begin{tabular}{|l|l|l|l|}
\hline & Chest & 1 & 16.7 \\
\cline { 2 - 3 } & MsTs & 1 & 16.7 \\
\hline
\end{tabular}

The analysis by descriptive statistics of the cases with hypercapnia shows that in the initial measurement of the RASS (or "RASS" English "Richmond Agitation-Sedation Scale") there are corresponding qualifications for drowsiness (-1), mild sedation $(-2)$ and sedation moderate $(-3)$ in equal percentages $(33.3 \%, \mathrm{n}=2)$. In the follow-up measurement, all cases were scored with scores greater than $-3(-2,-1,0$ and +1$)$, with $67.7 \%(n=4)$ corresponding to patients with mild sedation (-1) (Table 3 ).

Of the patients without hypercapnia, the vast majority had RASS equivalent to mild sedation $(-1)$, with $71.1 \%(\mathrm{n}=$ $27)$ in the initial measurement and $73.7 \%(n=28)$ in the follow-up measurement. The $7.9 \%(n=3)$ presented RASS equivalent to moderate sedation in the initial measurement and $2.6 \%(n=1)$ in the follow-up. There were no cases with RASS of 0 or +1 in this group (Table 4 ).

Table 3:-Results of patients with hypercapnia $(\mathrm{N}=6)$ according to their classification in the RASS scale.

\begin{tabular}{|c|c|c|c|}
\hline & & $\mathbf{n}$ & $\%$ \\
\hline \multirow{5}{*}{$\begin{array}{c}\text { RASS } \\
\text { Initial measurement }\end{array}$} & -3 & 2 & 33.3 \\
\hline & -2 & 2 & 33.3 \\
\hline & -1 & 2 & 33.3 \\
\hline & 0 & 0 & 0 \\
\hline & +1 & 0 & 0 \\
\hline \multirow{5}{*}{$\begin{array}{l}\text { RASS } \\
\text { Follow-up measurement }\end{array}$} & -3 & 0 & 0 \\
\hline & -2 & 4 & 66.7 \\
\hline & -1 & 0 & 0 \\
\hline & 0 & 1 & 16.7 \\
\hline & 1 & 1 & 16.7 \\
\hline
\end{tabular}

Table 4:-Results of patients without hypercapnia $(\mathrm{N}=6)$ according to their classification in the RASS scale.

\begin{tabular}{|c|c|c|c|}
\hline & & $\mathbf{n}$ & $\%$ \\
\hline \multirow{5}{*}{$\begin{array}{c}\text { RASS } \\
\text { Initial measurement }\end{array}$} & -3 & 3 & 7.9 \\
\hline & -2 & 8 & 21.1 \\
\hline & -1 & 27 & 71.1 \\
\hline & 0 & 0 & 0 \\
\hline & +1 & 0 & 0 \\
\hline \multirow{5}{*}{$\begin{array}{l}\text { RASS } \\
\text { Follow-up measurement }\end{array}$} & -3 & 1 & 2.6 \\
\hline & -2 & 8 & 21.1 \\
\hline & -1 & 28 & 73.7 \\
\hline & 0 & 0 & 0 \\
\hline & 1 & 0 & 0 \\
\hline
\end{tabular}

We analyzed the possibility of an association between different combinations of variables (hypercapnia-FC, hypercapnia-RF, hypercapnia-TA, hypercapnia-age, hypercapnia sex) without finding a statistically significant correlation ( $p>0.05)$. Likewise, due to the size of the sample, the correlation between hypercapnia and RASS was made by using Fisher's exact test, with a statistically non-significant result $(\mathrm{p}=0.13)$.

\section{Discussion:-}

In the practice of anesthesiology, monitoring of respiratory function is one of the most important safety pillars in patient care undergoing procedures under general anesthesia, deep sedation and pharmacological pain management, especially when it is based on opioids. The lack of controlled and directed studies regarding postoperative hypercapnia in patients with normal pulse oximetry, coupled with the dangerous notion that a patient with normal pulse oximetry finds an adequate ventilatory function in any scenario, means that, currently, The safety of some patients is compromised.

The magnitude of that risk is difficult to estimate. The results of the statistical analysis of the sample of 44 patients, from the study presented here, show that the frequency of postoperative hypercapnia in patients with normal pulse 
oximetry is significant (13.6\%), and could be by itself a relevant data medical and operational, in the contexts of critical medicine, perioperative and algology, because this finding exposes a possible deficiency in the management protocols of certain types of patients who are in situations of risk for the development of ventilatory depression. However, it is also necessary to mention that despite the high frequency of patients who presented one or more measurements with hypercapnia, they did not show detectable neurological, cardiorespiratory or hemodynamic deterioration, with the monitoring and monitoring used, where a statistically significant correlation was found, which is contrary to what was expected during the postoperative period of patients with hypercapnia data and, probably, of type II respiratory insufficiency.

By itself, the lack of statistically significant association between the variables is an interesting fact, which could be due to the small size of the sample. It is possible that there are other causes for risk scenarios generated by the indiscriminate administration of oxygen in some patients with compromised respiratory function, which are described below:

1. The lack of association between respiratory rate and hypercapnia, indicates that it is feasible that patients who presented hypercapnia and normal pulse oximetry could have been carriers of previous respiratory pathology, a fact that was not considered variable during the planning of this study.

2. No statistically significant association was found between the hypercapnia cases and variables such as respiratory frequency (RR), RASS and oxygen saturation by pulse oximetry, when it would be consistent to find a correlation between these cases and patients with altered RF, moderate sedation or deep and suboptimal percentages in pulse oximetry. A probable explanation, already mentioned in this document and described by other authors, is that the administration of supplemental oxygen has the capacity to mask states of ventilatory deficit in certain type of patients by means of increased oxygen supply, alterations in oxygen transport and $\mathrm{CO} 2$ (for hemoglobin and plasma), decreased ventilatory volumes and, finally, deterioration of the physiological response to the hypercapnia state itself.

3. It is possible that patients with a higher risk of perioperative morbidity and mortality (ASA III and emergency procedures) have not presented hypercapnia with normal pulse oximetry in the postoperative period because they receive more stringent monitoring and surveillance, since they are more prone to to show benefit of supplemental oxygen administration. It was the patients at lower risk (ASA I and II, and elective procedures) who exhibited hypercapnia with normal pulse oximetry, and to whom, despite being indicated, many times, they are not offered the monitoring and surveillance that It offers to those who are known to be in less stable conditions.

\section{Conclusions:-}

In accordance with the proposed objectives, the following is concluded:

1. EtCO2 monitoring was performed in 44 patients included in this study.

2. The frequency of hypercapnia with normal pulse oximetry during the postoperative period was $13.6 \%$.

3. No complications were found in the study sample of ventilatory origin.

4. No significant correlations were observed between the variables studied.

5. The monitoring of exhaled $\mathrm{CO} 2$ in the postoperative period should be considered systematically for patients undergoing procedures performed under general anesthesia and deep sedation, in patients under analgesia based on opioids (or other respiratory function depressants) and patients critics with risk of admission to the Intensive Care Unit.

6. The indiscriminate administration of supplemental oxygen could be a practice with harmful potential.

7. The Official Mexican Norm for the practice of anesthesiology could benefit from undergoing review regarding recommendations for the use and monitoring of capnography.

8. More controlled and targeted studies are needed to more reliably determine the relevance of the results obtained in this study. 


\section{Bibliográphic Refeerences:-}

1. Braunwald E, Fauci AS, Hauser SL, Jameson JL, Kasper D, Longo DL. Principios de medicina interna de Harrison. Decimosexta edición. Nueva York. McGraw-Hill; 2005.

2. Younsuck K. Update in acute respiratory distress syndrome. J Intensive Care. 2014;2(1): 2. DOI:10.1186/20520492-2-2. Disponible en https://www.ncbi.nlm.nih.gov/pmc/articles/PMC4267604/ [Visita de sitio de internet: 10 de enero de 2017].

3. ARDS Definition Task Force: Ranieri VM, Rubenfeld GD, Thompson BT, Ferguson ND, Caldwell E, Fan E et al. Acute respiratory distress syndrome: the Berlin Definition. JAMA. 2012;307(23):2526-2533. OI:10.1001/jama.2012.5669. Disponible en http://jamanetwork.com/journals/jama/article-abstract/1160659 [Visita de sitio de internet: 10 de enero de 2017].

4. Leaver S, Evans T. Acute respiratory failure. BMJ. 2007;335(7616): 389-394. Disponible en http://oxfordindex.oup.com/view/10.1093/med/9780199204854.003.1705_update_004 [accessado 10 de enero 2017].

5. McCarter T, Shaik Z, Scarfo K, Thompson LJ. Capnography Monitoring Enhances Safety of Postoperative Patient-Controlled Analgesia. American Health \& Drug Benefits. 2008;1(5):28-35. Disponible en https://www.researchgate.net/publication/264831425_Capnography_monitoring_enhances_safety_of_postopera tive_patient-controlled_analgesia [Visita de sitio de internet: 10 de enero de 2017].

6. Krauss B, Hess D. Capnography for Procedural Sedation and Analgesia in the Emergency Department. Ann Emerg Med. 2007;50(2),172-181. DOI:10.1016/j.annemergmed. 2006.10.016. Disponible en https://www.ncbi.nlm.nih.gov/labs/articles/17222941/ [Visita de sitio de internet: 10 de enero de 2017].

7. Vadivelu N, Mitra S, Narayan D. Recent Advances in Postoperative Pain Management. The Yale Journal of Biology and Medicine. 2010;83(1):11-25. Disponible https://www.ncbi.nlm.nih.gov/pmc/articles/PMC2844689/pdf/yjbm_83_1_11.pdf [Visita de sitio de internet: 10 de enero de 2017].

8. Dahan A, Aarts L, Smith T. Incidence, Reversal, and Prevention of Opioid-induced Respiratory Depression. Anesthesiology. 2010;112(1):226-38. DOI: 10.1097/ALN.0b013e3181c38c25. Disponible en http://anesthesiology.pubs.asahq.org/article.aspx?articleid=1932606 [Visita de sitio de internet: 10 de enero de 2017].

9. Karcz M, Papadakos PJ. Respiratory complications in the postanesthesia care unit: A review of pathophysiological mechanisms. Canadian Journal of Respiratory Therapy: CJRT. 2013;49(4):21-29. Disponible en https://www.ncbi.nlm.nih.gov/pmc/articles/PMC4456822/ [Visita de sitio de internet: 10 de enero de 2017].

10. Fajardo GE. Diario oficial de la federación (México). Norma Oficial Mexicana NOM-006-SSA3-2011, para la práctica de la Anestesiología. en http://dof.gob.mx/nota_detalle.php?codigo=5240668\&fecha=23/03/2012 [accessado 10 de enero 2017].

11. Committee of Origin: Standards and Practice Parameters (Approved by the ASA House of Delegates). Standars for basic anesthesic monitoring. en http://www.asahq.org/sitecore\%20modules/web/ /media/modules/digital\%20briefcase\%20apps/asa\%20practice $\% 20$ management/standards\%20guidelines\%20statements/anesthesia\%20care/standards-for-basic-anestheticmonitoring.pdf [Visita de sitio de internet: 10 de enero 2017].

12. Membership of the Working Party: Whitaker D, Booth H, Clyburn P, Harrop-Griffiths W, Hosie H, et al. Immediate post-anaesthesia recovery. 2013: Association of Anaesthetists of Great Britain and Ireland. Anaesthesia. 2013;68(3):288-97. DOI:10.1111/anae.12146. Disponible en http://onlinelibrary.wiley.com/. DOI:/10.1111/anae.12146/abstract [Visita de sitio de internet: 10 de enero 2017].

13. Kodali B. Capnography outside the operating rooms. Anesthesiology. 2013;118(1):192-201. DOI: 10.1097/ALN.0b013e318278c8b6.

Disponible

en http://anesthesiology.pubs.asahq.org/article.aspx?articleid=2034665 [Visita de sitio de internet: 10 de enero 2017].

14. Laserna E, Sibila O, Aguilar P, Mortensen E, Azueto A, Blanquer J, et al. Hypocapnia and Hypercapnia Are Predictors for ICU Admission and Mortality in Hospitalized Patients With Community-Acquired Pneumonia. Chest. 2012;142(5):1193-1199. DOI:10.1378/chest.12-0576. Disponible en https://www.ncbi.nlm.nih.gov/pmc/articles/PMC3494472/ [Visita de sitio de internet: 10 de enero 2017].

15. Yassin Z, Saadat M, Abtahi H, Rahimi Foroushani A, Peiman S. Prognostic value of on admission arterial PCO2 in hospitalized patients with community-acquired pneumonia. Journal of Thoracic Disease. 2016;8(10):2765-2771. DOI:10.21037/jtd.2016.10.21. Disponible en https://www.ncbi.nlm.nih.gov/pmc/articles/PMC5107471/ [Visita de sitio de internet: 10 de enero 2017]. 
16. Cook TM, Woodall N, Frerk C; Fourth National Audit Project:Major complications of airway management in the UK: Results of the Fourth National Audit Project of the Royal College of Anaesthetists and the Difficult Airway Society. Part 1: Anaesthesia. Br J Anaesth. 2011;106:617-31. DOI:https://DOI.org/10.1093/bja/aer058. Disponible en https://academic.oup.com/bja/article/106/5/617/279879/Major-complications-of-airwaymanagement-in-the-UK [Visita de sitio de internet: 10 de enero de 2017]

17. Cook TM, Woodall N, Harper J, Benger J; Fourth NationalAudit Project: Major complications of airway management in the UK: Results of the Fourth National Audit Project of the Royal College of Anaesthetists and the Difficult Airway Society. Part 2: Intensive care and emergency departments.Br J Anaesth. 2011;106:63242. DOI:https://DOI.org/10.1093/bja/aer059.

Disponible

en https://academic.oup.com/bja/article/106/5/632/279958/Major-complications-of-airway-management-in-theUK?sid=4c3b4ca4-c779-40df-9aa0-d130b2cf350d [Visita de sitio de internet: 10 de enero de 2017]

18. Ayas N, Bergstrom L, Schwab T, Narr B. Unrecognized severe postoperative hypercapnia: a case of apneic oxygenation. Mayo Clin Proc. 1998;73(1):51-4. DOI: http://dx.DOI.org/10.1016/S0025-6196(11)63619-7. Disponible en http://www.mayoclinicproceedings.org/article/S0025-6196(11)63619-7/fulltext [Visita de sitio de internet: 10 de enero 2017]. 